\title{
Sonographic Association of Cholelithiasis with Obstructive Jaundice in Adult Patients
}

\author{
Anosha Nasir Dar, Mahjabeen Liaqat, S. Muhammad Yousaf Farooq, Mehreen Fatima \\ University Institute of Radiological Sciences and Medical Imaging Technologies, Faculty of Allied Health \\ Sciences, University of Lahore, Lahore, Pakistan. \\ Corresponding Author: Anosha Nasir Dar \\ Corresponding Email: anoshanasirdar@gmail.com
}

\begin{abstract}
Background: Cholelithiasis is the commonest cause of obstructive jaundice and for the investigation of cholelithiasis and obstructive jaundice ultrasound is a gold standard modality. Obstructive jaundice is generally due to biliary obstruction, which is a blockage of the common bile duct or any duct that carries bile from the liver to the gallbladder and then enters into the small intestine. Objective: To determine sonographic association of cholelithiasis with obstructive jaundice in adult patients. Methodology: A cross sectional study was conducted among 138 individuals. All were young adults within the age range of 18-35 years. Data was collected from Civil Hospital Gujranwala city, by using simple random sampling technique. The examination was done with Toshiba Xario $3.5-5 \mathrm{MHz}$ curvilinear transducer. Gallbladder scan was started with the patient in the supine position from both subcostal and intercostal approaches. It was analyzed through SPSS version 24.0 and presented through frequency and percentages. Results: Total 138 individuals were included in this study. Out of 138 subjects, 69 individuals with cholelithiasis out of 69, 24 individuals with obstructive jaundice. And other 69 individuals without cholelithiasis in which 26 subjects presented with jaundice. It was found that females $(51.4 \%)$ were more commonly affected than males $(48.6 \%)$.Conclusion: It was concluded that cholelithiasis is one of the main causes of obstructive jaundice and ultrasound can easily diagnose the cases of cholelithiasis. It was found that females were more commonly affected than males.
\end{abstract}

Keywords: cholelithiasis, obstructive jaundice, jaundice, ultrasound.

DOI: $10.7176 / \mathrm{JHMN} / 72-04$

Publication date:March $31^{\text {st }} 2020$

\section{Introduction}

Gallbladder is an oval shaped organ found in the upper quadrant of the right abdomen. The width is approximately $4 \mathrm{~cm}$ and the length is between 7 and $10 \mathrm{~cm}$. anatomically, the gallbladder is located anteriorly on the undersurface of liver segments IV and V. ${ }^{1}$ Gallbladder has three parts; fundus, body and neck. ${ }^{2}$ Gallstone disease is a common disease. Gallstones can be classified into the following three types on the basis of their composition: cholesterol, pigment and mixed stones. ${ }^{3}$ Bile is produced in the liver and then deposited in the gallbladder. The high concentrations of bile salts, cholesterol or calcium can lead to the formation of gallstones. ${ }^{4}$ Epidemiological risk factors for the formation of gallstone cholesterol include age, gender, diet, obesity, decreased physical activity, rapid weight loss, and oral contraceptive use. ${ }^{5}$ Obstruction of the bile duct outlet caused by either a neoplasm or inflammation and pancreatitis, or as a result of a moving sludge or stones, can lead to gallbladder problems. Gallstone is one such particular disease, and its complications, such as cholecystitis, pancreatitis and cholangitis, are major public health issues around the world. ${ }^{6}$ Gallstones are small solid calculi found in the gallbladder, known as cholelithiasis. ${ }^{7}$ The problem begins with the stones entering the bile duct, and preventing the passage of bile. Many bile stones less than 2 to $2.5 \mathrm{~cm}$ pass through the normal gastrointestinal tract spontaneously and are excreted into the stools. ${ }^{8}$ when the stone is 2 to $5 \mathrm{~cm}$ in diameter it may get stuck in the bile duct and cause obstructive jaundice. ${ }^{9}$ Gallstones are well known to have risk factors that includes 5 F's made of female, fat, flatulence, fertile and 40 have been shown in numerous studies. Western studies have shown that ethnicity, genetics, gender $(\mathrm{F}>$ $\mathrm{M})$, age, obesity, fertility, metabolic disease, hepatitis $\mathrm{C}$, cirrhosis, high caloric intake are the contributing risk factors for gallstones. ${ }^{10,11}$ Another study reduces the risk of gallstone diseases due to fruit and vegetable intake and increase in the risks of gallstone diseases due to spicy foods, fried foods and cooking oils. ${ }^{12}$ In some studies, the prevalence of gallstone illness has not been seen as significant due to the vegan or non-vegetarian diets, intake of fruits, physical inactivity, HDL cholesterol, triglyceride levels and body mass index. ${ }^{13}$ Obstructive jaundice has been significantly associated with age and gender. ${ }^{14}$ Many risk factors for gallbladder disease have already been identified, such as ethnicity, fatty acids and carbohydrates, high-cholesterol diets, diabetes mellitus, hyperinsulinemia, sickle cell anemia, spinal cord injuries, Wilson's disease and metabolic syndrome, age, gender, female sex hormones, oral contraceptive use, obesity, and rapid weight loss. ${ }^{15,16}$

Obstructive jaundice is a common form of jaundice that occurs as bile flows into the intestine through bile ducts that are blocked by either gall stones or tumors and the most common cause of biliary obstruction is gallstones. ${ }^{17}$ The aim of this study is to find the relation between obstructive jaundice and gall stones in patients and also to create awareness of the possible complications; so, that morbidity can be reduced in the society. 


\section{Materials and Methods:}

A cross sectional study was performed in Civil Hospital Gujranwala city by using simple random sampling technique among 138 individuals. All were young adults within the age range of 18-35 years. The patients were investigated with a standard Toshiba Xario ultrasound system with curvilinear transducer $3.5-5 \mathrm{MHz}$ sector. The machine fixing such as total gain, focusing and depth was adjusted. Examination was started with the patient in the supine position. The gallbladder was scanned from both subcostal and intercostal approaches and the consent form was taken from the patients. Data was analyzed through SPSS version 24.0 and presented through frequency and percentages.

\section{RESULTS}

This cross sectional study was done in Civil Hospital Gujranwala city by using simple random sampling technique among 138 individuals. All were young adults within the age range of 18-35 years. A total of 138 individuals participated in this study with the minimum age of 18 years and the maximum age of 35 years, from which 69 were those having no cholelithiasis and 69 patients having cholelithiasis with mean age of $26.17(\mathrm{SD} \pm 4.76)$ and 27.78 ( $\mathrm{SD} \pm 4.71)$ respectively. Out of 69 individuals with no cholelithiasis, 68 were found with no obstructive jaundice and 1 individual was found with obstructive jaundice by mean age of 26.27 (SD \pm 4.72) and 19 years respectively. Out of 69 patients with cholelithiasis in which 46 having no obstructive jaundice and 23 having obstructive jaundice with mean age $26.89(\mathrm{SD} \pm 4.66)$ and $29.56(\mathrm{SD} \pm 4.38)$ respectively. (Table 1)

\section{Table 1}

Age

\begin{tabular}{lll|l|l|l|l} 
Cholelithiasis & Obstructive jaundice & Mean & $\mathrm{N}$ & Std. Deviation & Minimum & Maximu \\
\hline \multirow{2}{*}{ Absent } & Absent & 26.2794 & 68 & 4.72164 & 19.00 & 35.00 \\
\cline { 2 - 8 } & Present & 19.0000 & 1 &. & 19.00 & 19.00 \\
\cline { 2 - 8 } & Total & 26.1739 & 69 & 4.76802 & 19.00 & 35.00 \\
\hline \multirow{3}{*}{ Present } & Absent & 26.8913 & 46 & 4.66775 & 18.00 & 35.00 \\
\cline { 2 - 8 } & Present & 29.5652 & 23 & 4.38827 & 21.00 & 35.00 \\
\hline \multirow{2}{*}{ Total } & Total & 27.7826 & 69 & 4.71814 & 18.00 & 35.00 \\
\hline & Absent & 26.5263 & 114 & 4.68893 & 18.00 & 35.00 \\
\hline & Present & 29.1250 & 24 & 4.80319 & 19.00 & 35.00 \\
\hline & Total & 26.9783 & 138 & 4.79426 & 18.00 & 35.00 \\
\hline
\end{tabular}

The minimum and maximum age with mean and standard deviation shown in the table (table1)

\section{Table 2}

Gender

\begin{tabular}{|l|c|c|}
\hline & Cholelithiasis & Obstructive jaundice \\
\hline Gender & Present & Present \\
\hline Female & 36 & 13 \\
\hline Male & 33 & 11 \\
\hline & 69 & 24 \\
\hline
\end{tabular}




\section{Graph2}

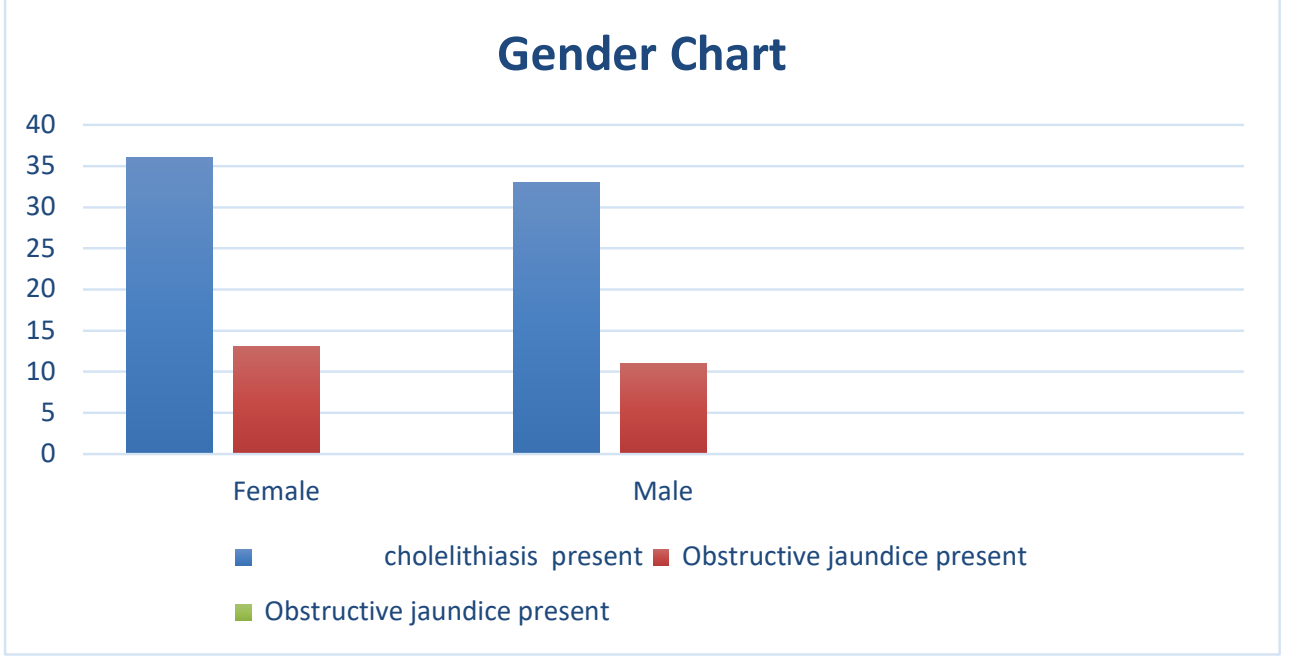

From 138 individuals, 69 were presented with cholelithiasis and out of these 69, 33 were males and 36 were females. And out of these 69 individuals 24 were presented with obstructive jaundice in which 11 were males and 13 were females in above table 2 (Table 2)

\section{Table no 3}

GALLBLADDER STONES SIZE (in cm)

\begin{tabular}{l|l|l|}
\hline Stones & Frequency & Percentage \\
no stone & 70 & 50.7 \\
\hline single stone & 37 & 26.8 \\
\hline two stone & 5 & 3.6 \\
\hline multiple stones & 26 & 18.8 \\
\hline Total & 138 & 100.0 \\
\hline
\end{tabular}

From total 138 subjects, $70(50.7 \%)$ subjects were found to have no stones, $37(26.8 \%)$ had solitary stones, $5(3.6 \%)$ had two stones, and 26(18.8\%) had multiple stones in above table(Table 3$)$ In 138 subjects, 114 individuals were found with no obstructive jaundice and 24 individuals had obstructive jaundice. Out of 114 individuals with no obstructive jaundice, 81 individuals had no yellowing of sclera and 33 had yellowing of sclera. In the 24 individuals with obstructive jaundice, all cases were found with yellowing of sclera. (Table 5)

Out of 114 individuals with no obstructive jaundice, 55 individuals had no symptom of fever and 59 were those who presented with fever. From the 24 individuals with obstructive jaundice, all 24 cases presented with fever. (Table 6)

Out of 114 individuals with no obstructive jaundice, 36 individuals had no abdominal pain and 78 were those with abdominal pain. From 24 individuals with obstructive jaundice, all 24 cases were found with abdominal pain. (Table 7)

Out of 138 subjects, $88(63.8 \%)$ individuals had no jaundice and 50(36.2\%) individuals had jaundice.(Table 8$)$ Association between cholelithiasis and obstructive jaundice was significant with p-value 0.000 which was less than 0.05 .

\section{DISCUSSION}

Obstructive jaundice is a specific type of jaundice, which may occur due to blocked bile ducts, caused by gallstones or bile duct tumors. Jaundice may be divided into three causes are referred to as therapeutic jaundice, while posthepatic causes or obstructive jaundice can be categorized as surgical jaundice. Yellowing of sclera, dark yellowbrown urine, yellowish skin, anemia and high levels of bilirubin are shown in patients with obstructed jaundice. Ultrasound is a gold standard technique for detecting gallstones. In this study of total 138 individuals with the age ranged 18-35 years and mostly 35 year's elders were more affected with obstructive jaundice, out total 69 were presented with cholelithiasis and females are more affected than males respectively, whereas according to Shaffer et al women are significantly more affected by gallstones than men and with increasing age further raise the prevalence in both sexes. 52 An other study performed by Gudelj Gracanin A et al, on Etiology and Epidemiology of Obstructive Jaundice in Continental Croatia according to that obstructive jaundice is the illness of elderly population which is also confirmed by the information on the average age of patients and also the frequency of illness is higher among female population and it was also found that the most frequent cause of obstructive jaundice 
are gallstones. ${ }^{18}$

In this study, out of 138 individuals 69 individuals were presented with cholelithiasis to which 24 were presented with obstructive jaundice and it was the most common cause of biliary obstruction. Khurram $\mathrm{M}$ et al performed a study on Endoscopic retrograde cholangio-pancreatographic evaluation of patients with obstructive jaundice in that study of the 226 patients, 117 (51.8\%) were males, and 109 (48.2\%) females, with their mean age being $51.8+/-16.6$ years, in that study common bile and pancreatic ducts were visualized in $81.8 \%$ and $68.1 \%$ patients respectively. According to the study growth/masses and stones were commonest causes of obstructive jaundice and Choledocholithias was common in males, while biliary channel related growth/masses were common in females ( $p$-value $=0.03$ ). It was also found that the most common cause of biliary obstruction is gallstones and that is similar to our findings. ${ }^{19}$

In our study, total individuals were 138, out which1 14 individuals with no obstructive jaundice, 55 individuals had no symptom of fever and 59 were those who presented with fever. From the 24 individuals with obstructive jaundice, all the cases presented with fever and it was the most common cause of obstructive jaundice. According to a clinical study on obstructive jaundice performed by the Prabakar et al, Patients admitted to the Department of General Surgery at Thanjavur Medical College were taken up for the study and the number of cases were 30 . Pain abdomen was present in $73.33 \%$ patients, dyspepsia in $60 \%$. Itching and clay colored in $53 \%$ of patients. Melena in $10 \%$ patients with 36 times increased risk for malignancy. Fever was present in a total of 16 patients $(53 \%)$ with benign condition- $70 \%$ and malignant condition $20 \%$ prevalence with no increased risk or statistical significance. It was concluded that fever was the most common cause of obstructive jaundice which was similar to our study. ${ }^{20}$

Out of 138 subjects included in our study, 114 individuals were found with no obstructive jaundice and 24 individuals having obstructive jaundice. Out of 114 individuals with no obstructive jaundice, 36 individuals had no abdominal pain and 78 were those with abdominal pain, from 24 individuals with obstructive jaundice there was no case found without abdominal pain. According to a case report and review of literature on difficult endoscopic diagnosis of a pancreatic plasmacytoma. Williet $\mathrm{N}$ et al found abdominal pain with one of the other major presenting symptoms, which is one of the associated diagnosis in our study. ${ }^{21}$

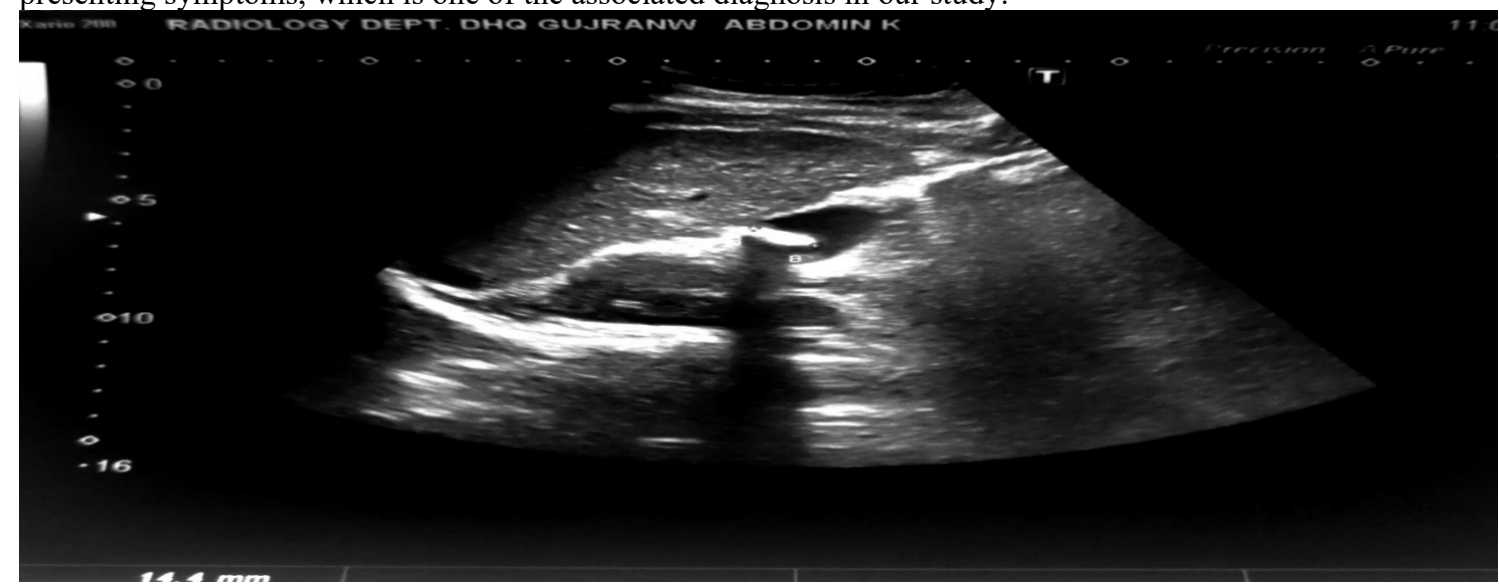

Fig 1: On ultrasound image of gallbladder shows $1.4 \mathrm{~cm}$ calculi with posterior acoustic shadowing.

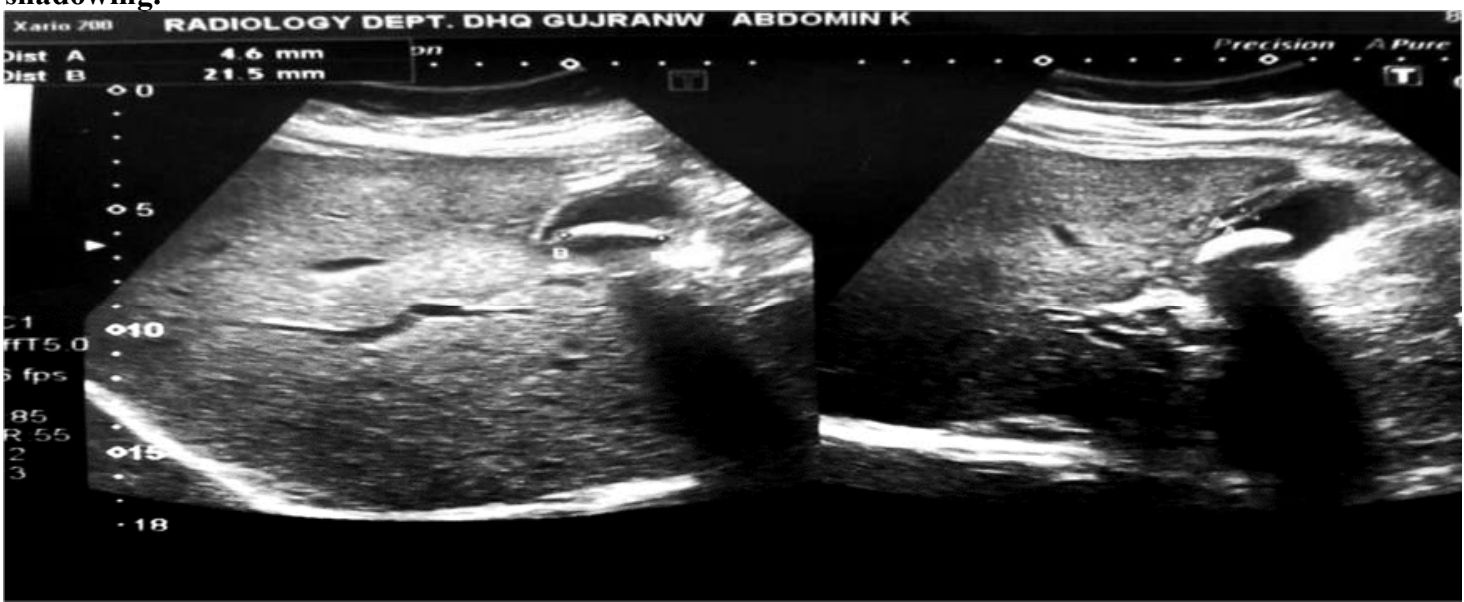

Fig 2: On ultrasound image of gallbladder shows $2.1 \mathrm{~cm}$ stone with posterior acoustic shadowing 
References

1. Jones MW, Young M. Anatomy, abdomen and pelvis, gallbladder. In Stat Pearls [Internet] 2019 Jan16.StatPearlsPublishing.

2. Channa NA. Gallstone disease: a review. Pakistan Armed Forces Medical Journal. 2008Jun30;58(2):197-208.

3. BeckinghamI.Gallstonedisease.Bmj.2001; 322(7278):91-4.

4. Panpimanmas S, Manmee C: Risk factors for gallstone disease in Thai population. JEpidemiol2009,19(3):116121.

5. Roglans N, Vázquez-Carrera M, Alegret M, Novell F, Zambon D, Ros E, Laguna JC, Sanchez RM. Fibrates modify the expression of key factors involved in bile-acid synthesis and biliary-lipid secretion in gallstone patients. European journal of clinicalpharmacology.2004Feb1; 59(12):855-61.

6. Rebholz C, Krawczyk M, Lammert F. Genetics of gallstone disease. European journal of clinical investigation. 2018 Jul;48(7):e12935.

7.Shaffer EA. Epidemiology of gallbladder stone disease. Best practice \& research Clinicalgastroenterology.2006Jan1;20(6):981-96.

8. Nakao A, Okamoto Y, Sunami M, Fujita T, Tsuji T. The oldest patient with gallstone ileus: report of a case and review of 176 cases in Japan. The Kurume medical journal. 2008;55(1+2):29-33.

9. Gameraddin M, Omer S, Salih S, Elsayed SA, Alshaikh A. Sonographic Evaluation of ObstructiveJaundice.

10. Randi G, Franceschi S, Vecchia CL. Gallbladder cancer worldwide. Geographical distribution andriskfactors.IntJCancer.2006,118(7):15911602.

Availablefrom:http://onlinelibrary.wiley.com/doi/10.1002/ijc.21683/full

11. Panpimanmas S, Manmee C: Risk factors for gallstone disease in Thai population. Epidemiology2009,19(3):116-121.

12. Chandran, A. P., Sivarajan, R., Srinivasan, V., Srinivas, M., \& Jayanthi, V., (2014). Risk profile for gallstone disease in southern Indian population: Is there anything new? Indian J Gastroenterol,33(3),257.http://dx.doi.org/10.1007/s12664-014-0453-3

13.Pagliarulo M, Fornari F, Fraquelli M, Zoli M, Giangregorio F, Grigolon A, Peracchi M, Conte D. Gallstone disease and related risk factors in a large cohort of diabetic patients. Digestive and liverdisease.2004Feb1;36(2):130-4.

14. Al-Atabi M, Chin SB, Luo XY. Experimental investigation of the flow of bile in patient specific cystic duct models. Journal of biomechanical engineering. 2010 Apr 1;132(4).

15. Shabanzadeh DM, Sørensen LT, Jørgensen T. Gallstone disease and mortality: a cohort study. International journal of public health. 2017; 62(3):353-60.

16. Biddinger SB, Haas JT, Bian BY, Bezy O, Jing E, Zhang W, et al. Hepatic insulin resistance directly promotes formation of cholesterol gallstones. Nature medicine. 2008;14(7):778.

17. Yu Z, Zhan J, Li C, Zhou H. Age and gender analysis of jaundice patients. J Biosciences Med. 2012Aug31;2(2):1e3.

18. Shaffer EA. Epidemiology and risk factors for gallstone disease: has the paradigm changed in the 21 st century? Current gastroenterology reports. 2005 Apr 1; 7 (2):132-40.3419.Gudelj Gracanin A, Kujundzic M, Petrovecki M, Rahelic D. Etiology and epidemiology of obstructive jaundice in Continental Croatia. Collegium antropologicum. 2013 Apr 3; 37(1):131-3. 20. Khurram M, Durrani AA, Hasan Z, Butt A Ashfaq $\mathrm{S}$. Endoscopic retrograde cholangio-pancreatographic evaluation of patients with obstructive jaundice. Journal of the College of Physicians and Surgeons--Pakistan: JCPSP. 2003 Jun; 13(6):325-8. 36 21.Williet N, Kassir R, Cuilleron M, Dumas O, Rinaldi L, Augeul-Meunier K, Cottier M, Roblin X, Phelip JM. Difficult endoscopic diagnosis of a pancreatic plasmacytoma: case report and review of literature. World journal of clinical oncology. 2017 Feb 10; 8(1):91. 